\title{
Mobile Solidarities and Precariousness at City Plaza: Beyond Vulnerable and Disposable Lives
}

\author{
VICKI SQUIRE \\ University of Warwick, UK
}

\begin{abstract}
This article explores how mobile solidarities are forged through precariousness at City Plaza, a disused hotel and collective refugee accommodation space in Athens, which has become a notorious site of resistance in the midst of the so-called "European migration crisis." Drawing on qualitative research carried out during 2016, the article explores how solidarities are created at this space in terms that not only challenge the abandonment of lives rendered disposable through camps, but also the rendering of lives vulnerable through humanitarian accommodation initiatives that seek to integrate those most in need of protection. While pointing to the significance of critical analyses of abandoned and disposable lives in the context of current migratory conditions across Europe, the article highlights the limitations of a frame of vulnerability specifically. It draws on the work of Judith Butler to argue that the relations of solidarity which are forged at City Plaza are better understood in terms of a form of precarity or precariousness that is shared, yet unevenly distributed.
\end{abstract}

KEYWORDS abandonment; disposability; vulnerability; precariousness; solidarity; migration

\section{Introduction}

This article explores how mobile solidarities are forged through precariousness at City Plaza, a disused hotel and collective refugee accommodation space in Athens, which has become a notorious site of resistance in the midst of the so-called "European migration crisis." Drawing on qualitative research carried out during 2016, it explores how solidarities are created at this space in terms that not only challenge the abandonment of lives rendered disposable through camps, but also the rendering of lives vulnerable through humanitarian accommodation 
initiatives that seek to integrate those most in need of protection. Terms such as abandonment, disposability, and precariousness have become increasingly relevant in critically conceptualising experiences associated with the mass flight of people from conditions such as conflict and warfare, extreme poverty and dispossession, environmental destruction and disaster (e.g., Davies, Isakjee \& Dhesi, 2017; Migrating Out of Poverty, 2016). The concepts of abandonment, disposability and precariousness are explored here against the backdrop of another term that has dominated wider debates around the plight of the displaced: the concept of vulnerability. The article highlights how governing subjects through vulnerability reduces subjects to victims and overlooks the harms that are produced through governing practices (see also Squire et al., 2017). Drawing on the work of Judith Butler (2004), it argues that the relations of solidarity which are forged at City Plaza differ in important ways from humanitarian accommodation initiatives, and are better understood in terms of a form of precarity or precariousness that is shared, yet unevenly distributed.

City Plaza has been occupied since April 2016 by a collective of refugee, student, and solidarity activists. It opened in May 2016 in order to provide accommodation for people otherwise abandoned in camps. Collectively organised in its daily operation, all those living at City Plaza are involved in the community's decision-making process through various crossrepresented assemblies. Distinct from institutional accommodation providers such as UNHCR, City Plaza includes people not on the basis of their vulnerability, but rather in terms of the diversity that they bring to the collective. Solidarity in this regard is an on-going project; one which is not without its difficulties, but which this article argues nevertheless facilitates appreciation of how diverse "precarious lives" can come together in terms that challenge processes of governing which produce people as disposable and as vulnerable. While many are stranded in camps and the "lucky few" are incorporated within humanitarian accommodation initiatives on the basis of their vulnerability, this article shows how in City Plaza people come together in solidarity to create a space where people arriving to Greece can begin to rebuild their lives.

The research on which this article draws was undertaken from May to July 2016, as part of the second phase of the collaborative project Crossing the Mediterranean Sea by Boat: Mapping and Documenting Migratory Journeys and Experiences [Crossing the Med] (Squire et al., 2017). The project conducted 257 in-depth qualitative interviews with 271 people who recently arrived to European Union (EU) states without authorisation by boat, or who have tried or plan to come to the EU from Turkey via this route. The overarching aim of the project is to assess the impact of European policy initiatives on people they effect most directly, namely those making the precarious journey toward Europe by boat. The research emphasises the importance of taking into account the journeys and experiences, as well as the understandings, expectations, concerns, claims 
and demands of people on the move. ${ }^{1}$ A total of 30 interviews were carried out in Athens, with 12 of these carried out with participants living at City Plaza specifically. The analysis draws both on interviews with those living in City Plaza as well as with those living in camps and other forms of housing in Athens. ${ }^{2}$ It also draws on the author's observations during a visit to City Plaza in May 2016, and on interview material and discussions with residents and activists during visits to Athens in May and November 2016.

The analysis in this article is developed along three lines: in relation to experiences of what is referred to as "abandonment as disposable lives;" in relation to experiences of what the article calls "humanitarian integration as vulnerable lives;" and in terms of experiences of what it names as "mobile solidarities as precarious lives." Reflecting on some of the insights of JeanLuc Nancy (1991), Achille Mbembe (2003), and Henri Giroux (2006), amongst others, the article stresses the significance of critical diagnoses of abandoned and disposable lives in the context of current migratory situations across Europe and in Greece more specifically. Going further, it also highlights the limitations of a frame of vulnerability, which is employed in humanitarian efforts to integrate those most in need of protection. By contrast, the article emphasises the importance of an analysis that engages the concept of "precarious lives" (Butler, 2004), and shows how the solidarities formed at City Plaza can be analysed in such terms. Reflecting on connections between the work of Julia Kristeva and Judith Butler, it considers how Kristeva's (2010) discussion of shared vulnerability can be developed with reference to Butler's (2004) notion of precarious lives as a means by which to understand how solidarity emerges in City Plaza under conditions that are marked - but not consumed - by

\footnotetext{
${ }^{1}$ The majority of our research participants arrived in 2015 and 2016. Some arrived prior to this period and via differentiated routes, yet became stranded in the sites where we carried out our research. Phase 1 of research involved 136 interviews with a total of 139 participants on three island arrival sites - Kos, Malta and Sicily - while Phase 2 involved 121 in-depth qualitative interviews with a total of 131 participants carried out in Athens, Berlin, Istanbul and Rome. For the purposes of this article, the analysis focuses on the conditions within Greece and Athens more specifically, which is important given that in 2015 a sudden increase in arrivals followed by the closure of onward routes left many new arrivals stranded in this region. However, it is also important to emphasise that the experiences documented in this article with regard to conditions in camps and humanitarian accommodation initiatives are not wholly unique to Greece or Athens. Indeed, the project findings point to similarities across various sites in the European Union (Squire et al., 2016a, 2016b, 2017).

${ }^{2}$ These interviews were undertaken by an Arabic and Greek-speaking team researcher in the language of the participant's choice, and were either later translated and transcribed or were conducted with a translator into English/Greek where required and then transcribed in English. The Athens-based interviews on which this article directly draws were manually analysed by the author and are also in the process of being coded using NVivo for use by the research team. Phase 1 data has already been coded using NVivo while Phase 2 data has been analysed manually by the research team prior to being coded for more detailed analysis. Given the sensitivity of the interview data, transcripts are not available for use beyond the research team, and strict guidelines related to anonymity and confidentiality are in place for the project team in order to protect the identity and use of data provided by research participants.
} 
conditions of shared precariousness yet uneven precarity. Beyond the sharing of vulnerability (in Kristeva's terms), this requires that attention is paid to precariousness or precarity as a historicised means of governing that defines some lives as more valuable or "grievable" than others (in Butlers terms). The article closes by considering how City Plaza can be interpreted as challenging such governing practices through the formation of mobile solidarities (Squire, 2011) based on "communities of sentiment" (Rosanvallon, 2011) that are grounded in a politics of presence.

\section{Abandonment as Disposable Lives}

The concept of abandonment has been heavily theorised from a legalpolitical perspective, and is particularly influential in Migration and Border Studies scholarship (e.g., Lee, 2010). Such works have drawn in particular on Giorgio Agamben's (1998; 2005) theorisation of the "ban" and the production of "bare life" as that which can be killed but not sacrificed. Yet the specific connection between abandonment and disposability, or what I discuss here in terms of disposable lives, might be traced to earlier works such as Jean-Luc Nancy's notion of abandonment in relation to sovereign power as "an order, a prescription, a decree, a permission, and the power that holds these freely at its disposal" (Nancy, 1993, p. 44). Moreover, conceptions of abandonment and disposability have been further examined through an analysis of the biopolitical governing of life and death. For example, Elizabeth A. Povinelli's (2011) work on Economies of Abandonment indicates that abandonment is not simply a legal given, but forms a political process which is implicated in the global distribution of life and death. One way of understanding this is in terms of what Slavov Zizek (2015 n.p.), in a recent interview terms a "new form of apartheid" in which "entire populations are rendered disposable on a daily basis." This resonates with Achille Mbembe's (2003) discussion of necropolitics as a paradigm in which life is subjugated to the "power of death," a conceptual intervention that has been important to scholars of migration who seek understanding of the delineation between lives that are "disposable" and those which are not (De León, 2015). Migration scholars of the "periphery" in particular have drawn on Mbembe's insight that necropolitics involves a distinctly colonial logic whereby "entire populations" become the focus of destruction and akin to the "living dead" (Mbembe, 2003, pp. 27-30). This has been approached as a way to understand the conditions under which many precarious migrations from the global South to the global North occur (Estevez, 2014).

It is not difficult to see why ideas of abandonment and disposability have been important to migration scholars in the context of an international scene whereby the lives of under-privileged people on the move appear to be disregarded by many of the over-privileged. As Qusay Loubani (2016, May 
24, n.p.), a Palestinian refugee from Syria who travelled to Greece by boat via Turkey and whom I met in a refugee squat during a visit to Athens in November 2016, describes in relation to the Idomeni camp: "Everything around here has turned into lines. Standing in that line with the others, the only thing I thought about was to take a deep look at the dark sky and try to make my waiting time go by quicker." Providing first-hand detail of the inhumane treatment he and others experienced in the notorious Idomeni camp on the Greek-Macedonian border in an openDemocracy article titled "Idomeni: A Devils Game" (Loubani, 2016, May 24), the publication of Qusay's testimonial is rare but his experience is not. The interviews from Crossing the Med include numerous accounts of inhumane and humiliating living conditions in both informal and formal camps, which negatively impact the physical, mental and emotional health of people arriving to Europe, as well as their family and communal relations (see Figure 1). Being stuck, stranded or abandoned is a recurring theme in this regard.

As in Qusay Loubani's testimonial, many of our research participants describe a situation of being stuck or at an impasse:

I wasn't expecting that I would be in this position ever, and especially with three children. I feel myself roaming from place to place, from place to place.... I was expecting that I would arrive. I knew that they wouldn't immediately take me to my husband but wasn't expecting this, here, being stuck. (ATH02.26, p. 11)

This 28-year old Syrian mother of three infant children describes her experience on arrival to Greece as one of being stranded and wandering without direction. As such, the quotation is suggestive of a situation whereby the mother's purpose in life has been lost. This can be interpreted as reflecting a condition of being rendered disposable through abandonment, as life is left on hold or put "to waste" (Giroux, 2006). In his analysis of the political response to Hurricane Katrina in the US, Henri Giroux (2006) talks precisely about a biopolitics of disposability through which people are "made waste." He describes how making human beings superfluous has been integral to slavery, colonialism and totalitarianism, and is reflected in forces that have "given up on the sanctity of life for those populations rendered 'at risk' by global neoliberal economies ... [which] ... work in diverse ways to render some groups as disposable and privileges others" (Giroux, 2006, pp. 182-183). Pointing both to the longer duration and contemporary significance of disposability, Giroux's work provides a poignant framework for interpreting many testimonies documented by Crossing the Med. 


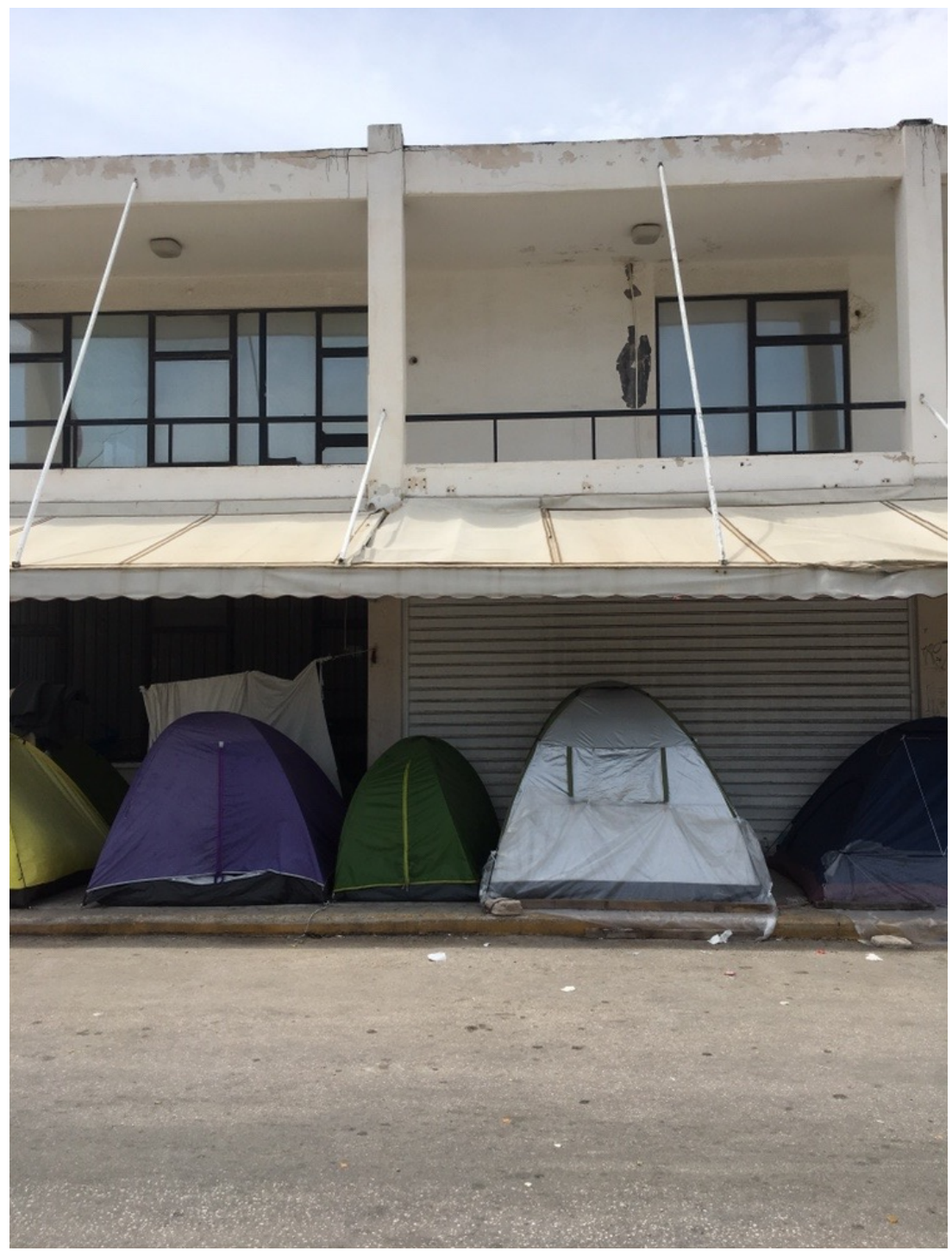

Figure 1. Tents in shade outside Elliniko Arrivals Hall, an informal camp at a disused airport in Athens (Photo: Vicki Squire)

What the 28-year old Syrian mother participant's statement above also points to is the ways in which this experience does not simply happen in predictable ways to people of the "peripheries" or to those whose underprivilege is long standing. It can also happen unexpectedly. This woman "wasn't expecting ...[to]... be in this position ever," reflecting also an 
expectation that her treatment in Europe would not be so dire. In other words, a person who at one moment knows privilege can suddenly find herself as left or made to "waste." Disposibility is thus a more generalised condition, with experiences of the abandonment of lives made disposable familiar to many people arriving to the European Union (EU) amidst a socalled "migration crisis" over recent years, whether they expected it or not. Going further, we might go so far as to argue that the conditions within Greece over recent years have been marked by a situation in which those who "weren't expecting it" faced rapid devaluation of their lives in the face of a spiralling financial "crisis." This article refers to a situation of generalised crisis as a means to highlight the significance of a context whereby various so-called crises intersect, and whereby uncertainty is a widespread condition. As we will see in the next section, a situation of generalised crisis can also be understood as a backdrop for the development of humanitarian accommodation initiatives that seek to integrate the most vulnerable. ${ }^{3}$

\section{Humanitarian Integration as Vulnerable Lives}

The situation for people on the move who arrive to dire conditions in the EU has led to many interventions by non-governmental and international organisations seeking to support the vulnerable. In the Greek context during the period of our research, UNHCR (United Nations High Commissioner for Refugees) was a key actor in this regard. UNHCR employ vulnerability criteria in order to work out how to prioritise support and housing for the "most needy" new arrivals. Hence, factors such as age, gender and disability are taken into account to provide accommodation to those deemed as most in need, as are more specific conditions such as if a woman is pregnant or breastfeeding, if a person has particular medical needs, or if a person is classified as a shipwreck, torture or trafficking victim. Paradoxically, such "victims" or vulnerable new arrivals became the lucky few out of around approximately 55,000 people stranded in Greece in 2016, since they had opportunities that allowed them to escape camp living.

Philip Armstrong (2016) has recently suggested that charity responds to abandonment as a condition which needs to be overcome. From this angle, abandonment reflects vulnerability, whereby victimhood and voicelessness prevail. However, many people on the move don't want to be incorporated as humanitarian victims in order to escape the camps, and instead simply seek conditions where they can live meaningful lives. As a 29-year old mother of four from Syria seeking to reach her eldest child in Germany

\footnotetext{
3 "Crisis" is used as a term in this article with caution, given the contested definition of the term and forms of emergency governing that crisis situations involve (see Brassett \& Vaughan-Williams, 2012).
} 
explains:

I want our message to reach the whole world. We are not coming here to beg! We are coming to work hard and raise our children. We are not coming to be humiliated. I want us to reach a better level. You see us waiting in line for food, but it's not in our control. What happened to us [in Syria] was not our doing. What more can I say?... That's the situation we have reached. A truly tragic situation. (ATH02.33, p. 18)

Similarly, a 25-year-old Syrian man told us:

I am not asking the government of Greece to deal with me like a Greek citizen. Just [for] justice as a human being. And as a refugee I am not asking for a hotel or apartment or a salary. (ATH02.13, pp. 11-12)

What these testimonies indicate is that many new arrivals reject the politics of pity (Aradau, 2008) and care (Ticktin, 2011) that predominates when they become integrated as vulnerable humanitarian subjects under conditions of generalised crisis. While some of the people we interviewed in Athens did make claims to safety, homes, work and support, such demands were not articulated in terms of victimhood but rather as a means to enable them to continue their lives. As the quotations here suggest, demands to justice through free movement and family reunification were much more prevalent, and thus are indicative of the differences between a humanitarian approach to integration that governs subjects based on their vulnerability, and the claims or demands of many new arrivals.

It is worth noting that vulnerability is not a concept that is used without caution or reflection by NGOs within the field, as a report on immigration detention by The Association for the Prevention of Torture/UN High Commission for Refugees (cited in Shaw, 2016) indicates. Listing a range of vulnerability factors, this report highlights how vulnerability can increase or decrease according to external factors, emphasising in particular how a lack of liberty and information in detention conditions, uncertainty about the future, and difficult relations for particular groups within detention can heighten vulnerabilities. This is picked up by Stephen Shaw's government report on detention in the UK, in which he cites Detention Action $(2014$, p. 20) in raising concerns about the difficulties of defining vulnerability:

... the concept of vulnerability is so vexed that it perhaps makes more sense to speak of a crisis of harm in detention. It seems clear that, more than ever before, detention in the UK is harming people. This harm is frequently severe, whether or not the person was categorisable as vulnerable before they were detained. (Shaw, 2016, p. 81)

More than simply highlighting the problems of vulnerability, this statement goes further to reject the concept entirely and replace it with the concept of 
harm. This is important because it emphasises that vulnerability is not a fixed condition, but remains reflective of a social and political context and thus of conditions that are created through institutionalised practices. In the UK case this refers to detention conditions, whereas in the Greek case in 2016 we can see this in terms of camps and other forms of sub-standard accommodation conditions.

As a concept, vulnerability is particularly significant to contexts marked by formations of under- and over-privilege. Julia Kristeva (2010) examines this in some detail both from a philosophical vantage point as well as from the perspective of her experience as a mother of a disabled child and longterm practicing psychoanalyst. She situates vulnerability as a fourth term to the triad liberty, equality, fraternity, and questions whether respect for a vulnerability that cannot be shared might form the grounds for sharing a more essential vulnerability, one which is inherent to the body of the speaking subject. She says:

I am convinced that humanism - which has always been in search of itself, from its emergence in the past to its crises or revitalisations today and in times to come - can find a chance to revitalise itself in the battle for the dignity of the disabled by constructing what is still sorely lacking: respect for a vulnerability that cannot be shared. My ambition, my utopia, consists of believing that this vulnerability reflected in the disabled person forms us deeply, or, if you prefer, unconsciously, and that as a result, it can be shared. Could this humanism be the 'cultural revolution' with which to construct the democracy of proximity that the postmodern age needs? (Kristeva, 2010, p. 252)

In this discussion of vulnerability, Kristeva raises caution against a form of charity that seeks to integrate those defined as disabled without an "interaction" between the "disabled" and the "able" subject, and without a questioning of the "able subject" in terms that lead to a "personal rebirth" (Kristeva, 2010, p. 253). While expressing admiration and gratitude for charities that support and provide care for the disabled in the face of state failures to do so, she also raises caution about the generous philosophy of caring and support on which such actions are based. In particular, she argues that these are taking "the risk of infantilising the disabled person" (Kristeva, 2010, p. 257).

So how does Kristeva understand this risk of infantilisation? "Something seems to be missing from this lovely 'integration'...," she notes, "...there is no sharing" (2010, p. 253). To put it in other terms, where support and care for the vulnerable do not involve an engagement that reflects back on both the vulnerabilities and privileges of the supporter or the carer as well, unequal relations of over- and under-privilege are simply reproduced. Kristeva thus employs vulnerability here in terms that highlight some of the problems of the concept as a frame of governing subjects in charitable terms. In a similar way, we might read humanitarian integration as involving infantilisation by incorporating new arrivals within 
accommodation initiatives on the basis of their vulnerability. As the statements of our research participants above indicate, this relation is one that new arrivals are unwilling to accept. It is for this reason that City Plaza is so important for people seeking to rebuild lives, and it is also for this reason that rethinking how the intervention can be analysed against the concept of "vulnerability" is critical.

\section{Mobile Solidarities as Precarious Lives}

While the majority of people arriving to Greece in 2015 and 2016 found themselves abandoned in camps (formal and informal), and while the lucky few have been integrated in humanitarian accommodation on the basis of their vulnerability, some are housed in occupied accommodation such as City Plaza (see Figure 2). There are a range of refugee squats in Athens and across Greece, which are supported by a strong leftist movement. These provide alternative accommodation for people arriving to a situation in which many are abandoned as disposable lives. For example, when I met Qusay Loubani (cited above) in November 2016, he was living with his wife in the disused Hotel Oniro in Athens, along with 139 other new arrivals, all of whom were from Syria apart from one Afghan family of four. Comparing their experience of Hotel Oniro with that of Idomeni, Qusay somewhat wryly described the disused hotel as a "paradise" where they are "treated like a human being, not animals" (see also Loubani, 2016). Yet City Plaza is distinctive compared to sites such as Hotel Oniro, because as more than simply a refugee squat it is occupied by a collective of refugee, student, and solidarity activists, and involves a relatively sophisticated approach to communal living and community decisionmaking. Relations of under- and over-privilege are by no means absent here. For example, these surfaced in discussions that I had with activists about the difficult process of initially choosing who can enter the community, and in refugee residents' claims that some are treated differently than others by activist "hosts." However, City Plaza also creates the conditions for a sharing of lives in terms that enable reflection on vulnerabilities that cannot be shared, to borrow from Kristeva. The communal approach to organised living is significant in this regard.

As a disused hotel that was closed for several years, City Plaza has been occupied since April 22 $2^{\text {nd }}, 2016$. The project is supported by various activists, with approximately 20 local and 20 visiting cross-European activists living on-site in late May 2016. From May $2^{\text {nd }}$ of the same year, City Plaza began hosting refugees who arrived prior to the EU/Turkey Deal of March 2016. In late May 380 refugees were living in the reused hotel. City Plaza is not funded by the state or by NGOs, but is self-funded and self-run. While other refugee squats often set up schedules to share tasks such as cooking and cleaning, City Plaza goes further to organise regular 
decision-making assemblies for residents, education for resident children, and political events to develop understanding of the wider politics within which the lives of those present are situated. This renders City Plaza unique in the challenge it poses to the abandonment of disposable lives under conditions marked by a condition of generalized crisis. It also renders City Plaza unique in the challenge it poses to the integration of vulnerable lives through a politics of victimhood, charity or pity.

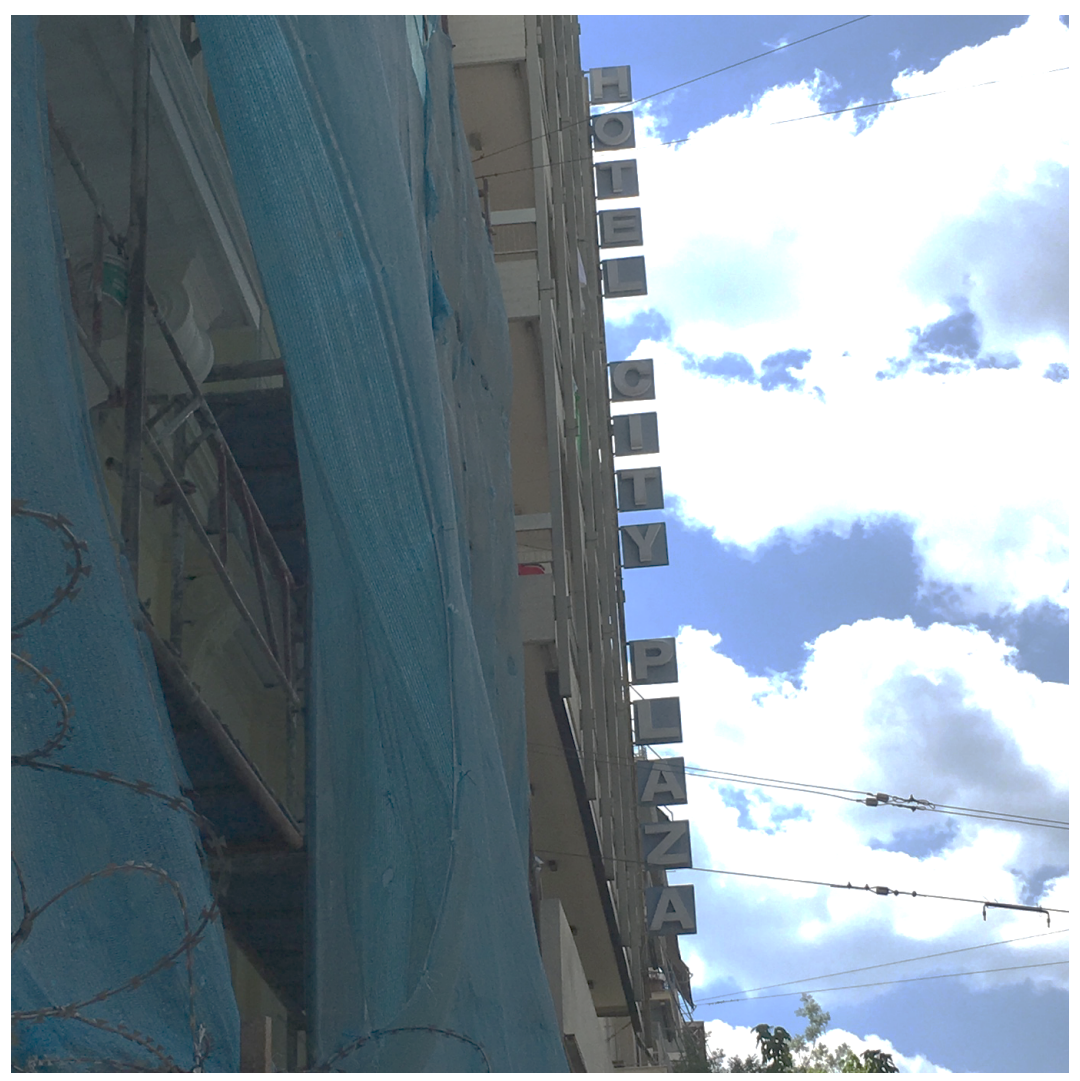

Figure 2. Hotel City Plaza, a disused hotel occupied by refugees and activists in central Athens (Photo: Vicki Squire)

By contrast to humanitarian accommodation providers such as UNHCR, City Plaza includes people not on the basis of vulnerability criteria, but rather in terms of the diversity that they bring to the collective. Questions about why people migrated are not a factor in identifying those to be accommodated. Instead, attention is paid to ensuring a mix of nationalities, a gender balance, and a combination of religious beliefs. In late May 2016 there were around 20 single parents, six single men, 10 unaccompanied 
minors, four people with extreme disabilities, several pregnant women as well as three new-born babies present on site. There were also people with particular skills to offer to the community, including teachers and translators. While a humanitarian integrative approach risks infantilising residents, as Kristeva (2010) forewarns, City Plaza engages refugee residents as contributing to a shared life, rather than requiring assistance to escape abandonment through living as victims with specified vulnerabilities. City Plaza is thus grounded in a culture of mutual respect that supports people to go out from the community and find their own way forward in the city. As co-founder of City Plaza, a long-standing resident of the Athens and refugee from Afghanistan, Nasim Lomani, explained during my visit in May: "We don't want to make a ghetto within the city - even if it is a nice ghetto."

Uniquely, then, City Plaza is a place whereby people arriving to Greece otherwise either abandoned and treated as disposable or infantilised and integrated as vulnerable victims - can begin to rebuild their lives. Residents, in other words, have shared lives without being defined by their legal and political (non)status or by a social status marked by the category of vulnerability. What this article suggests is that more than simply a shared essential vulnerability (in Kristeva's terms), this represents the coming together of people on the basis of their precarious situations, yet without defining existence according to vulnerability or victimhood. It is here that the work of Judith Butler is particularly instructive. She theorises precarious lives in terms of a violent process of framing and representational effacement, which distinguishes between grievable and non-grievable lives through rendering "the other" inhuman - or as never human in the first place (Butler, 2004, pp. 147-148). Sharing with Kristeva a concern about the ways in which the constitution of human life involves inherent (or ontological) uncertainty, Butler shifts attention from the unconscious drivers of insecurity to the social and political dynamics through which fears about being subject to violence (or being a subject of violence) are translated into processes of division and violation. An emphasis on the social and political production of precarious lives, in other words, is a conceptual tool that enables us to sharpen our critical exploration of the ways in which precariousness (as an inherent ontological uncertainty or instability) is put to work in practical and material terms as a divisive governing mechanism.

There are different ways in which precarity or precariousness is understood in social science literatures, with some relating it to a broader sense of existential instability or "ontological insecurity" and others more specifically linking it to labour precarity under conditions of "neoliberal globalisation" that involve workplace exploitation (see Lewis, Dwyer, Hodkonson \& Waite, 2015). Butler's definition does not exclude either of these understandings of the term, yet focuses primarily on forms of governing that divide people between those of worth and those without 
worth (or as grievable and ungrievable lives, in her terms). Theorised in this way, precariousness provides a conceptual frame by which to critique the more widely used term of vulnerability, which is defined here as a humanitarian mode of governing subjects that connects to wider processes of abandonment. Butler conceives precarity in relation to a mechanism of government or governing that involves the uneven distribution of precariousness. The inherent precariousness of collective life, she suggests, involves processes of representation that can render injustice hidden through a legitimisation of unequal precarity as "self-evident." Focusing on precarious lives in relation to precariousness (as a collective ontological condition) and precarity (as an uneven material and practical condition) in this regard signals an appreciation of the ways in which processes of governing subjects through vulnerability or precariousness is inherently divisive, despite not always appearing as such on the surface.

It is the contention of this article that the occupation of City Plaza precisely makes visible the shared experience of precariousness understood both in terms of an ontological and collective condition generally, as well as in terms of a historically-specific practical and material condition that is unevenly distributed (and which is thus also pertinent to questions of labour exploitation). To clarify, what this article advocates is a shift from the conceptual frame of vulnerability to precariousness in the interpretation and conceptualisation of City Plaza. This shift represents an appreciation of precariousness as shared (in ontological terms) and of precarity as unequally experienced (in practical or material terms). Such an interpretation is in line with Kristeva's understanding of vulnerability, yet employs Butler's terminology. Going further, a shift to precarity or precariousness over vulnerability is important because it emphasises how precariousness is more than simply an inherent or ontological condition, as it involves a historised form of governing that differentiates subjects in terms that value some over others. In the case of the situation in Athens during the so-called "migration crisis" of $2016,{ }^{4}$ this form of governing occurred not only through processes of abandonment that leave people to perish in camps, but also through a humanitarian rendering of vulnerability that rests on a division between those more or less in need of protection. This framing of vulnerability masks the harms of governing frameworks that seek to address the very vulnerabilities that they produce, which is why a shift to the language and conceptual frame of precarity and precariousness is critical.

An appreciation of the significance of this conceptual or analytical shift to precarity and precariousness is apparent if we consider how the collective itself narrates the history and ownership of City Plaza prior to its current occupation. As a hotel, City Plaza was closed some seven years

\footnotetext{
${ }^{4}$ At the time of writing, this crisis was on-going in terms similar to when it was widely reported as such, although media and wider political interest in the issue had waned somewhat.
} 
before its current occupation due to the company running it having gone bankrupt. Workers at the hotel were granted ownership of mobile equipment such as furniture and kitchen equipment within City Plaza via a court order, as compensation for their lost wages. However, the owner of the hotel allegedly did not permit the workers entry to the hotel in order to secure this equipment, and on the transformation of the building to a "refugee accommodation space" the previous hotel employees permitted use of the equipment by those present. In response to a more recent dispute over a water bill for the property, residents of "City Plaza Refugee Accommodation Space" wrote an open letter to the owner of the building highlighting both the injustices faced by the previous employees of City Plaza and those facing the current residents. In this letter, the harms resulting from unequal precarity are directly problematised. The letter challenges the owner by saying: "...the thing is that you are very rich. And, you know, in our opinion, wealth is not a neutral individual happy condition, because it is the result of poverty for many more." Going on, the letter poses a challenge to the owner: "...you may wish to opt for the way of modest abundance and dignity, by allowing refugees to live in your property for as long as needed, as did the former hotel employees with the mobile equipment" (Open Letter to Ms. Aliki Papachela, 2017, n.p.).

What is significant here is that the open letter highlights both aspects of precarity that are shared, as well as inequalities that emerge through the uneven experience of precariousness. For example, while there are particular barriers for new arrivals to secure labour opportunities, there are also difficulties in this regard for host populations as well - particularly for Greece in a situation of generalised crisis. The situation of the prior employees of the hotel exemplifies this, particularly in the face of the relative wealth of the hotel owner. Yet the emphasis on the wealth of some coming at the expense of others also highlights a wider sense of precariousness as shared, in that wealth is not seen as universalisable and hence an inherent uncertainty remains for all regardless of their current circumstances. In the face of this inherent precariousness, the granting of access to mobile equipment by the previous employees of City Plaza is narrated in the letter as indicative of an appreciation of a shared precariousness in the face of the uneven distribution of precarity. An analysis of precarious lives in this respect enables an analysis of City Plaza as distinct from those interventions that involve abandoned or vulnerable lives, as discussed earlier in this article.

What this article suggests, then, is that City Plaza can be interpreted as an intervention that forges solidarities on the grounds of precarity or precariousness, grounded in a politics of presence. In other words, City Plaza represents is an intervention that rejects the division of lives between those of the over- and the under-privileged, forging what I have elsewhere termed mobile solidarities that are grounded in presence and participation rather than a form of community that divides people via legal or cultural 
means (Squire, 2011). Importantly, it does so in terms that acknowledge a precariousness that is shared and a situation in which precarity is differentially-distributed, yet without defining the existence of those who are often acted upon as disposable according to their vulnerability. In the final section of analysis, the article turns to explore the significance of interpreting City Plaza in such terms, drawing specifically on the testimonies of those living there at the time of our research.

\section{Making a Difference}

So why is it significant that City Plaza involves the formation of mobile solidarities between those present on the grounds of shared precariousness and uneven precarity rather than through a process of integration grounded in care for the vulnerable? For a significant proportion of the residents we spoke to, City Plaza was described as good accommodation (ATH02.06, p. 6; ATH02.07, p. 8; ATH02.28, p. 14; ATH02.41, p.), as a safe place (ATH02.13, p. 11), as wonderful accommodation (ATH02.15, p. 9) and as having excellent conditions (ATH02.20, p. 18; ATH02.31, p. 3) with amazing help (ATH02.21, p. 13). Several referred to the importance of having a private bathroom (ATH02.20, p. 18; ATH02.13, p. 9; ATH02.27, p. 6), particularly in contrast to conditions within camps where some described experiences of sharing facilities with up to 800 other people (ATH02.20, p. 18). Despite these positive experiences, however, City Plaza was not presented as a flawless paradise. Some of our research participants noted problems such as racism between groups (ATH02.07, p. 8), a lack of order in relation to the preparation of food (ATH02.28, p. 14), and even some initial fighting (ATH02.33, p. 12). As the Syrian mother cited earlier describes:

At the beginning there was a lot of fighting over the food. A lot. Before they made the cards, they were discriminating between the Afghans and the Syrians. I'm not saying that all Syrians are good and all Afghans are bad. In the end, all of us are humans. Really. Our heart should be one. (ATH02.33, p. 12)

This quotation captures some of the ambiguities of City Plaza. As an ongoing project, it does not fully escape the pressures, divisions and difficulties that are evident in the wider context. However, at the same time, City Plaza presents opportunities for a movement beyond such pressures, based on collective living that brings people together in terms that highlight a situation of precarity and precariousness that is both collectively experienced and unevenly distributed.

The mobile solidarities that are formed at City Plaza also reflect how mechanisms of governing through vulnerability intersect with conditions of precariousness and experiences of precarity. Many of the people that we spoke to for our Crossing the Med project reflected on their divided 
families, and on the emotional difficulties associated with such experiences of estrangement in a context where family reunification was thwarted by policy. City Plaza in this regard is both a site that enables us to reflect on how precarity is a produced condition, as well as a site that provides opportunities for new formations of what Pierre Rosanvallon (2011) calls communities of sentiment. In line with an understanding of mobile solidarities as grounded in presence rather than legal or cultural belonging (Squire, 2011), these communities of sentiment are evident in terms that do not fit with simple nationalistic or familial formations through which community is often associated:

I came here [City Plaza] and they helped me a lot. The woman at the reception and the guys. Personally, if I work 24 hours here in the hotel, I feel it's a little for their goodness. We have a room, me and my wife and my children. It's as if I returned to life again. They put me in a position that I can take care of my wife and kids and find my way. Also, the most beautiful person that I saw in my life was here. I felt she was my mother and more than my mother. My mother. That's the feeling and more than that I'm not able to express. (ATH02.21, p. 13)

This 26-year old Palestinian Syrian barber has been unable to see his parents since he fled to Jordan in 2013, and as an expression of gratitude to his "new family" at City Plaza willingly contributes to the functioning of the collective. Continuing, he describes how for some people such family divisions are literally unbearable, and so he seeks to connect with others precisely to avoid such "disintegration":

There's also a guy here [at City Plaza], a friend, he is disintegrating bit by bit. This person, his wife and his child are in Sweden and he is here. He and his wife are separated. He's following the wrong path. As long as I have strength, I will do anything I can to assist the European people to help my refugee brothers, whether they are Afghan or Pakistani...I don't discriminate. I don't look at religious extremism. I only look at one thing: we are human. Our breath comes in and out. OK, I'm a Muslim, and my brother is a Christian. I don't like categories. Many people have criticised me for this but I don't want to discriminate between this person and that person because we are all human. My father and mother, may God protect them, raised me on something, which is food. If I share a plate with you, I will never betray this even if my head is on the line. I will never do anything...I will help anyone. I work [as a barber in the community] every day for 4 hours, I shave any person, I try and help any person, I try and clean. I don't retract from work because I didn't see a hotel here, I saw a family. I feel like I'm a member, that that is my sister and that is my sister and that is my friend. (ATH02.21, pp. 14-15)

There are a series of complexities to this testimony that are beyond the scope of this article to examine in full, yet what is important for our purposes is that City Plaza is described in terms that counter the relations of estrangement which are particularly pressing for people separated from 
their families, while providing opportunities for a new "sentiment of feeling" between people that are otherwise divided rather than united. This reflects a sense of how the sharing of precarious lives at City Plaza enables relations of support that do not escape unequal relations of privilege, but that can nevertheless open up opportunities for such relations to be confronted and challenged in terms that enable people to rebuild lives even amidst a situation of generalised crisis.

Indeed, it is the importance of sharing that is highlighted as part of the broader ethos of City Plaza by another 26-year old man from Syria:

The conditions at the hotel [City Plaza] are really good. They are trying as much as they can to help us, to live with us, to live our injury with us. Our joy is their joy, our sadness is their sadness. This is what I've seen. They are good people, I love them. (ATH02.24, p. 10)

While the uneven experience of precarity clearly comes through in the positionalities implied between "helper" and "helped" in this statement, what also comes through is the sharing of precarious lives through a solidaristic ethos. This ethos is grounded not in family or relationships of kinship and cultural uniformity, but in a shared struggle that builds what we might call "community" through presence and participation rather than through what Jean-Luc Nancy (1991) describes in terms of a "community as communion" (see also Squire, 2011, p. 301).

Residence within City Plaza requires agreement to abide by a basic set of rules to ensure the safety of residents (including the agreement to participate in the daily activities of the collective and to show respect and solidarity toward others), rather than a simple contractual agreement. Yet as the quotations above indicate, City Plaza is more akin to a home and a family for many of those living there (see also Squire, 2017). For some, this is not enough and the focus remains on moving away from City Plaza, whether to meet family (as for the "disintegrating" father and husband discussed by our research participant above), or whether to move forward in life in a broader context of generalised crisis:

There is food to eat. Yes, you have a room, you have food. Until when? You cannot stop your mind. You are not sure how long you will stay here, one month, two months, one year. There is no work, no studying. One of the reasons that I left my country was to continue my studies. The hotel is good but I hope the future will be better. (ATH02.41, p. 8)

For others, however, City Plaza is a place that provides a new home worth staying in - at least for now (see Figure 3):

...we'll stay here, we're happy, teaching people, a humanitarian service, thank

God staying in the hotel. (ATH02.20, p. 18) 


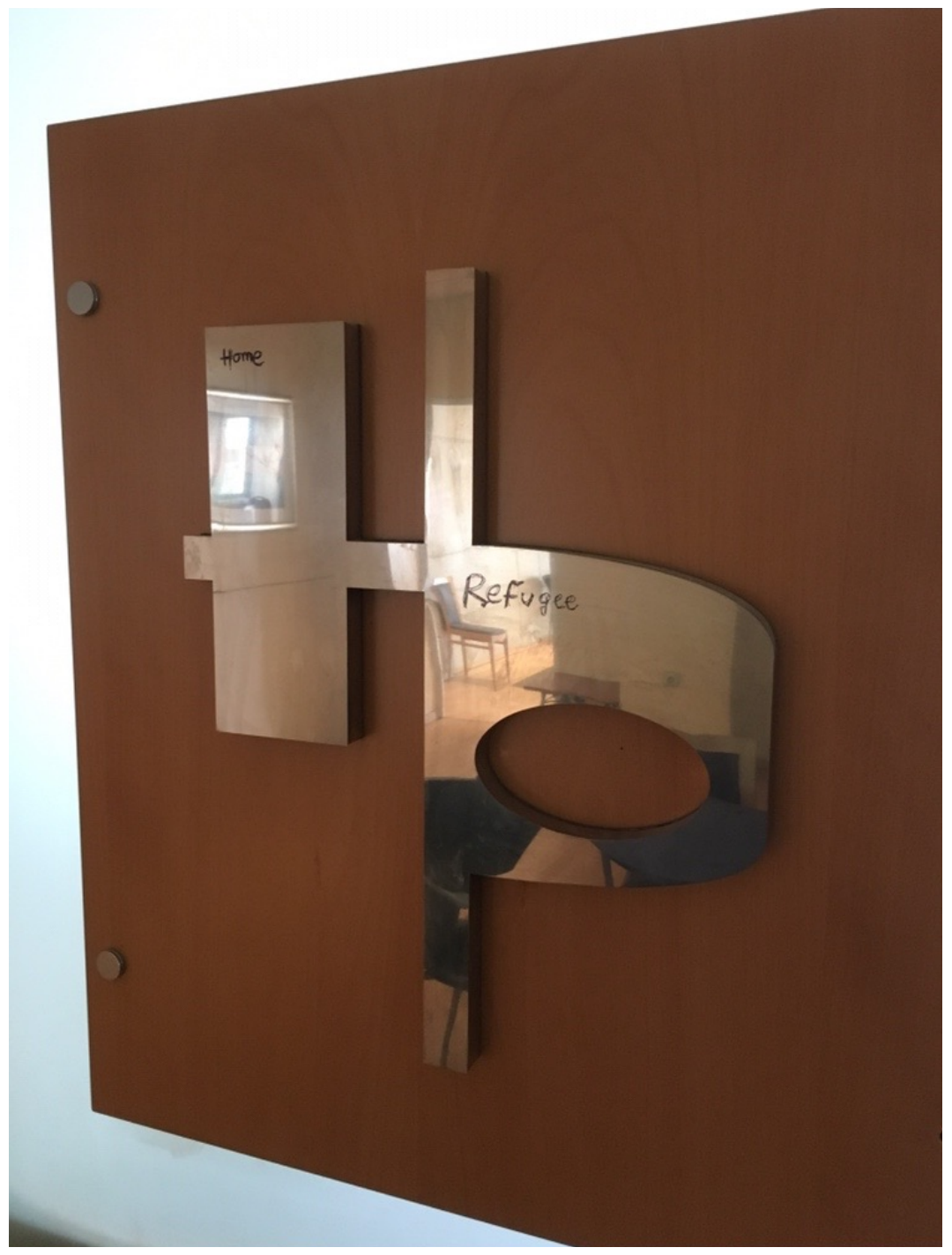

Figure 3. Hotel Plaza, "Refugee Home" (Photo: Vicki Squire)

While the first statement was made by a 19-year old single Afghan man seeking to reach family and friends in Europe independently, the latter was made by the wife of a young Syrian couple who are both teachers waiting to be relocated within Europe by institutional agencies. Rather than recipients of humanitarianism, however, the wife presents the couple as providing a humanitarian service through their presence within the hotel. The gratitude that she expresses could be interpreted as an expression of 
gratitude for the opportunity that City Plaza offers the couple as an alternative to their integration as vulnerable lives. This refusal of a form of governing through vulnerability along with the charitable approach that this implies is evident in the demand of her husband to travel freely, rather than providing sustenance:

I'll make it simple. Arrange the affairs of the refugee, and don't give him anything. Tell him 'tomorrow you will travel and I won't give you food or water', and he will say 'I'm fine with that.' (ATH02.20, p. 18)

\section{Conclusion}

This article has drawn on qualitative research carried out during 2016 in order to unpack the unique contribution of City Plaza, a disused hotel and collective refugee accommodation space in Athens. It has highlighted the differences between City Plaza and camps in which people arriving to the EU are "abandoned as disposable lives," as well as the differences between City Plaza and humanitarian accommodation initiatives in which people are "integrated as vulnerable lives." In so doing, the article has explored the limits of vulnerability as a conceptual frame and has drawn on Judith Butler's conceptualisation of precarious lives as a means to make the case for an alternative way of analysing City Plaza. Such analysis pays attention to the ways that collective life, grounded in a shared precariousness and appreciation of the unevenness of precarity, forms an important challenge to processes of governing of subjects through vulnerability. The article has analysed the testimonies of those living at City Plaza to make the case for such an analysis, and has suggested that the intervention is characterized by the formation of mobile solidarities (Squire, 2011) in which communities of sentiment (Rosanvallon, 2011) are formed through a politics of presence. The significance of City Plaza in this regard can be seen in its initiation of a form of shared living that challenges the failures of governmental and charitable responses to the so-called migration crisis, in the midst of a generalised crisis marked by widespread uncertainty.

Clearly City Plaza is just one site, which alone cannot meet the needs of the up to 55,000 stranded people in Greece. Indeed, this is precisely why the intervention seeks more than simply to provide a living space members of the collective also connect with and initiate mobilisations beyond City Plaza in order to effect wider change: "We can't solve the problem," Nasim Lomani tells me, "but we can be ready [to act in solidarity] when we are needed." In the face of governmental attempts to respond to the situation through mechanisms such as asylum registration procedures and relocation to other EU member states (or deportation for those not qualifying for relocation or protection), people "made [to] waste" (Giroux, 2006) or rendered vulnerable became increasingly impatient. 
Demands for family reunification and open borders were frequently voiced during our research. By contrast, people often rejected victimhood by appealing for justice and by demanding opportunities to continue meaningful lives. City Plaza is a space where people come together to make such claims, forming new communities of sentiment beyond community as communion. This article has argued that this can be understood in terms of mobile solidarities that are grounded in presence and participation (Squire, 2011), or what Julia Kristeva (2004) refers to as a democracy of proximity. Coming together in solidarity in this regard is not to be idealised, but nevertheless opens up an understanding of how precarious lives that are imperfectly shared can challenge the production of vulnerable or disposable subjects. Such is the importance of an intervention that emerges in the midst of crisis, at a now-notorious site of political struggle within a disused hotel in Athens.

\section{Acknowledgements}

This article is based on research carried out as part of the Economic and Social Research Council funded project, Crossing the Mediterranean Sea by Boat: Mapping and Documenting Migratory Journeys and Experiences, ES/N013646/1. This is a collaborative project, and sincere thanks are extended to the whole research team including the co-investigators, researchers, translators and transcribers. Particular thanks are extended to Angeliki Dimitriadi who led on research in Athens and made initial connections with City Plaza, and to Vasiliki Touholiotis who undertook the majority of interviews on which this article is based. In addition, sincere thanks are extended to the editors and anonymous reviewers of this article, as well as to Tahseen Kazi and Philip Armstrong who provided insightful comments on earlier drafts.

\section{References}

Agamben, G. (2005). State of exception. Chicago, IL: University of Chicago Press.

Agamben, G. (1998). Homo sacer: Sovereign power and bare life. (D. Heller-Roazen, Trans.). Stanford, CA: Stanford University Press.

Aradau, C. (2008). Rethinking trafficking in women: Politics out of security. Basingstoke, UK: Palgrave.

Armstrong, P. (2016). Notes on abandonment. Manuscript submitted for publication.

Brassett, J., \& Vaughan-Williams, N. (2012). Crisis is governance: Sub-prime, the traumatic event, and bare life. Global Society, 26(1), 19-42.

Butler, J. (2004). Precarious life: The Power of mourning and violence. London: Verso.

Davies, T., Iskajee, A., \& Dhesi, S. (2017). Violent inaction: The necropolitical experience of refugees in Europe. Antipode, 49, 1263-1284.

De León, J. (2015). The land of open graves: Living and dying on the migrant trail. Oakland, CA: University of California Press. 
Detention Action. (2014). The state of detention: Immigration detention in the UK in 2014. London: Detention Action. Retrieved from http://detentionaction.org.uk/wordpress/wpcontent/uploads/2014/10/The.State_.of_.Detention.pdf

Estevez, A. (2014). The politics of death and asylum discourse: Constituting migration politics from the periphery. Alternatives, 39(2), 75-89.

Giroux, H. (2006). Reading Hurrican Katrina: Race, class and the biopolitics of disposability. College Literature, 33, 171-196.

Kristeva, J. (2010). Liberty, equality, fraternity, and . . vulnerability. (J. Herman, Trans.). Women's Studies Quarterly, 38(1/2), 251-268.

Lee, C. T. (2010). Bare life, interstices and the third space of citizenship. Women's Studies Quarterly, 38(1/2), 57-81.

Lewis, H., Dwyer, P., Hodkinson, S., \& Waite, L. (2015). Hyper-precarious lives: Migrants, work and forced labour in the Global North. Progress in Human Geography, 39(5), 581585.

Loubani, Q. (2016, October 13). Small illegal paradise. openDemocracy. Retrieved from https://www.opendemocracy.net/5050/qusay-loubani/small-illegal-refugee-paradise

Loubani, Q. (2016, May 24). Idomeni: A devil's game. openDemocracy. Retrieved from https://www.opendemocracy.net/5050/qusay/idomeni-devil-s-game

Mbembe, A. (2003). Necropolitics. Public Culture, 15(1), 11-40.

Migrating out of Poverty. (2016) Precarious Migration: Voices of Undocumented Cambodian Migrants. Falmer, UK: University of Sussex \& Nicola Streeten. Retrieved from http://migratingoutofpoverty.dfid.gov.uk/files/file.php?name=precarious-migrationcomic-rgb-web.pdf\&site $=354$

Nancy, J. C. (1993). The birth to presence. (B. Holmes, Trans.). Stanford, CA: Stanford University Press).

Nancy, J. C. (1991). The inoperative community. Minneapolis, MN: University of Minneapolis Press.

Open Letter to Ms Aliki Papachela, owner of the City Plaza Hotel. (2017, April 26). Enough is Enough. Retrieved from https:/enoughisenough14.org/2017/04/26/refugeesgr-athensopen-letter-to-ms-aliki-papachela-owner-of-the-cityplaza-hotel/

Povinelli, E. (2011). Economies of abandonment: Social belonging and endurance in late liberalism. Durha, NC: Duke University Press.

Rosanvallon, P. (2011). The new social question: Rethinking the welfare state. (B. Harshav, Trans.). Princeton, NJ: Princeton University Press.

Shaw, S. (2016). Report into the welfare in detention of vulnerable persons: A report to the Home Office. London: OGL. Retrieved from https://www.gov.uk/government/uploads/system/uploads/attachment_data/file/490782/52 532_Shaw_Review_Accessible.pdf

Squire, V., Dimitriadi, A., Perkowski, N., Pisani, M., Stevens, D., \& Vaughan-Williams, N. (2017). Crossing the Mediterranean Sea by doat: Mapping and Documenting migratory journeys and experiences, Final project report. Coventry, UK: University of Warwick. Retrieved from https://warwick.ac.uk/fac/soc/pais/research/researchcentres/irs/crossingthemed/ctm_final report_4may2017.pdf

Squire, V., Dimitriadi, A., Perkowski, N., Pisani, M., Stevens, D., \& Vaughan-Williams, N. (2016a). Crossing the Mediterranean Sea by boat: Evidence Briefing 2. Coventry, UK: University of Warwick. Retrieved from http://www2.warwick.ac.uk/fac/soc/pais/research/researchcentres/irs/crossingthemed/out put/crossing_the_med_evidence_brief_ii.pdf

Squire, V., Dimitriadi, A., Perkowski, N., Pisani, M., Stevens, D., \& Vaughan-Williams, N. (2016b). Crossing the Mediterranean Sea by boat: Evidence Briefing 1. Coventry, UK: University of Warwick. Retrieved from http://www2.warwick.ac.uk/fac/soc/pais/research/researchcentres/irs/crossingthemed/out put/evidence_paper.pdf

Squire, V. (2017, May 2). The European "Migration Crisis": Families Split and Reconfigured Across Divides. Discover Society, 44. Retrieved from 
https://iscoversociety.org/2017/05/02/the-european-migration-crisis-families-split-andreconfigured-across-divides/

Squire, V. (2011). From community cohesion to mobile solidarities: The City of Sanctuary network and the Strangers into Citizens campaign. Political Studies, 59(2), 290-307.

Ticktin, M. (2011). Casualties of care: Immigration and the politics of humanitarianism in France. Berkeley, CA: University of California Press.

Zizek, S. (2015). The disposable life: Full interview [Video file]. Retrieved from https://www.youtube.com/watch?v=lxE9xgftGzo 